\title{
EXPANSÃO URBANA E A OCUPAÇÃO DA MICROBACIA DO CÓRREGO ÁGUAS DA VEADA - OURINHOS/SP
}

\author{
Weslei Reghini de Moraes ${ }^{(a)}$, Andrea Aparecida Zacharias ${ }^{(b)}$ \\ (a) IGCE - Pós-graduação em Geografia, Unesp, wesleirm@yahoo.com.br \\ (b) IGCE - Pós-graduação em Geografia, Unesp, andrea@ ourinhos.unesp.br
}

\section{EIXO: BACIAS HIDROGRÁFICAS E RECURSOS HÍDRICOS: ANÁLISE, PLANEJAMENTO E GESTÃO}

\begin{abstract}
Resumo
Este trabalho objetiva discutir o processo histórico de ocupação da microbacia do córrego Águas da Veada localizado no município de Ourinhos/SP e o produto final será um mapeamento representando os momentos de urbanização, respeitando um intervalo de classes de 10 anos. Com isso espera-se chegar a um panorama de como se deu a expansão urbana na microbacia e quais as consequências socioambientais e econômicas causadas pelos tipos de uso ali presentes. Este resultado será mediado por técnicas de geoprocessamento e o software empregado será o ArcGis 10.
\end{abstract}

Palavras chave: Ourinhos; urbanização; microbacia; geoprocessamento.

\section{Formação histórica do espaço urbano de Ourinhos/SP}

Conhecer o processo de formação é imprescindível para a compreensão do atual espaço geográfico urbano. A análise dos acontecimentos e agentes sociais envolvidos no processo de expansão da urbe traz a possibilidade de compreender mais profundamente os motivos pelos quais a paisagem urbana se apresenta como é na contemporaneidade. A partir dessa perspectiva as intervenções urbanas podem ser mais eficientes socioambiental e economicamente. O objetivo aqui proposto é elaborar um breve histórico da ocupação da microbacia do córrego Águas da Veada situado no município de Ourinhos/SP (figura 1), e o resultado final esperado é um mapeamento representando a evolução da mancha urbana nesta área, seguindo as orientações metodológicas alinhadas à proposta de Martinelli (2005). 


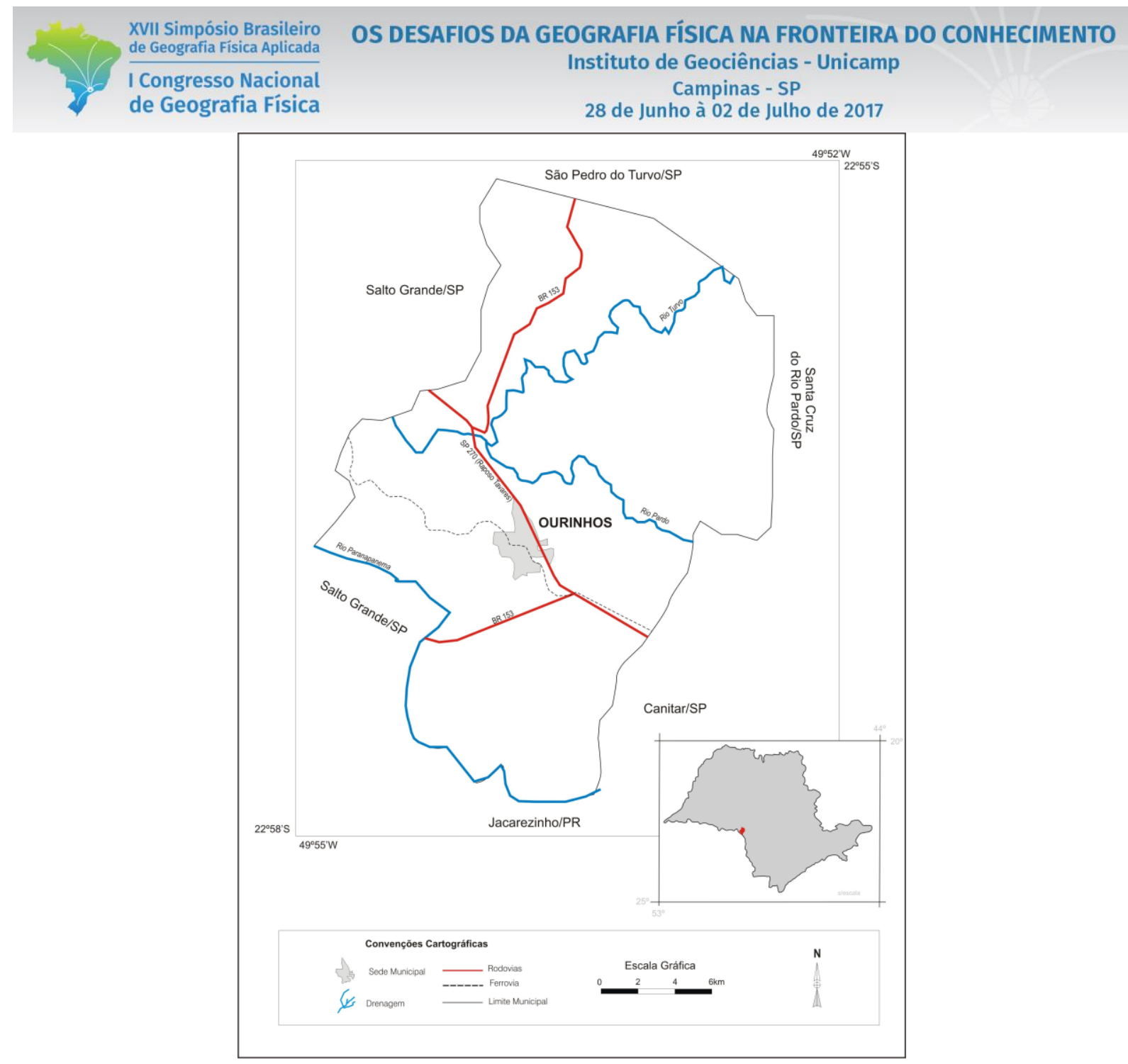

Figura 1: Localização do município de Ourinhos/SP. Fonte: MORAES, 2016.

Ourinhos recebe a classificação de cidade média e apresenta dinâmica socioeconômica e espacial bastante interessante, até mesmo por conta da recente ascensão do grau de importância das cidades médias na rede urbana.

A expressão "cidade média" é empregada pelo IBGE para classificar cidades que possuam entre 100.000 e 500.000 habitantes. A ONU, no entanto, considerava em 1994, aglomerações entre 100.000 a 1 milhão de pessoas como cidade média (SOARES, 1998). O critério demográfico, entretanto, sofre variações temporais e espaciais, atualmente a ONU classifica como médias aquelas cidades que possuam entre 100.000 e 3 milhões de habitantes, já para a Comunidade Europeia o valor flutua entre 100 e 250 mil habitantes, por sua vez o congresso Ibero Americano de Urbanismo delimitou valores entre 20 mil e 500 mil habitantes (CONTE e FRESCA, 2011). Percebe-se que o critério demográfico é bastante diverso e isso 
pode ser explicado pelas diferenças nas escalas geográficas. Países europeus, por exemplo, pela escala geográfica menor, adotam valores populacionais diferentes do Brasil, que apresenta escala geográfica muito maior. Outros critérios empregados na classificação das cidades médias (CONTE e FRESCA, 2011), e muitas vezes considerados mais importantes que os valores populacionais, pura e simplesmente, são a posição hierárquica da cidade na rede urbana, sua especialização econômica, a presença de comércio e serviços e de redes de transporte.

As cidades médias têm atraído pessoas e investimentos em razão da saturação das grandes cidades que geram deseconomia de aglomeração. Elas trazem soluções para o crescimento populacional, o equilíbrio da economia e a qualidade de vida, e essas ideias têm sido bastante difundidas pela mídia. De acordo com Filho e Serra (2001, p. 1 - 34), as cidades médias são concebidas, pelos habitantes das grandes cidades, como lugares de novas oportunidades econômicas, livres das grandes distâncias e do trânsito caótico, com qualidade de vida elevada, ao mesmo tempo são, para as pessoas das pequenas cidades, locais culturalmente atrativos, com disponibilidade de mercadorias e serviços, além de oportunidades de emprego. Daí a tendência de êxodo das grandes cidades e diminuição populacional das pequenas urbes, as pessoas vêm procurando as cidades médias, é certo que por diferentes motivos, para se fixarem e tentarem uma vida melhor. Estes são alguns dos motivos pelos quais é possível explicar o recente dinamismo de crescimento ourinhense.

As bases teóricas para o resgate histórico deste trabalho estão nas obras de Del Rios (1992), e de Boscariol (2008), os quais apresentam grandes contribuições para o conhecimento da História e da Geografia de Ourinhos, vale pontuar que não objetivamos resgatar em detalhes e à exaustão a história do município, isso já foi feito por outros autores.

O surgimento de Ourinhos está inserido no contexto da colonização do Oeste Paulista, no fim do século XIX, como alternativa econômica ao fim do ciclo do ouro. Inicialmente a economia desta região do estado estava voltada à subsistência ligada à pecuária. O município de Ourinhos surge em 1918, emancipado de Salto Grande, configurando-se como importante nó entre São Paulo e Paraná, impulsionado pela cafeicultura e pela ferrovia, que à época era propriedade da "Sorocabana Railway Company". O fluxo de pessoas pela região aumentou e a recente infraestrutura demandou novos investimentos como pequenos comércios, serviços de estadia e indústrias semi-artesanais Boscariol (2008).

Entre as décadas de 40 e 50 do século XX, a cafeicultura já bastante enfraquecida pelos reflexos da crise de 29, cede espaço à agroindústria canavieira, e também neste momento, ascende o modelo rodoviário no Brasil, diminuindo em muito os investimentos em ferrovias no país. Com o novo modelo econômico 
intensifica-se o êxodo rural e a busca por novas formas de sobrevivência nos centros urbanos Boscariol (2008).

Além do processo de êxodo rural é interessante frisar o significativo crescimento populacional apresentado pelo município:

Tabela 1: Crescimento vegetativo de Ourinhos/SP

\begin{tabular}{|lcccccccccc|}
\hline \multicolumn{8}{|c|}{ Crescimento vegetativo de Ourinhos SP'1920 - 2016 } \\
Ano & 1920 & 1940 & 1960 & 1980 & 2000 & 2007 & 2014 & 2015 & 2016 \\
População & 4.273 & 13.123 & 34.702 & 59.499 & 93.693 & 107.129 & 109.489 & 110.282 & 111.059 \\
\hline
\end{tabular}

Fontes: BOSCARIOL, 2008; IBGE, 2016. Organização: MORAES, 2016.

É possível associar o grande crescimento populacional ao aumento do nível de importância do município de Ourinhos no contexto regional, fundamentalmente em função da instalação de importantes rodovias e também da manutenção da ferrovia para transporte de carga. Ourinhos está na rota das rodovias Raposo Tavares (SP - 270), Orlando Quagliato (SP - 327), que conecta a Raposo Tavares à Rodovia Castelo Branco (SP - 280), além da Transbrasiliana (BR - 153), sendo servida também pela antiga Estrada de Ferro Sorocabana, atualmente sob concessão da América Latina Logística (ALL), tal fato contribui para maior fluidez de pessoas e mercadorias, tornando o município em um importante entroncamento rodoferroviário.

Com duas décadas de existência, mais da metade da população do município já vive na zona urbana. Avançando mais cinquenta anos o percentual de habitantes urbanos já alcança os 90\%, demonstrando forte tendência de urbanização (tabela 2).

Tabela 2: Êxodo rural e aumento da população urbana

\section{Êxodo rural e aumento da população urbana}

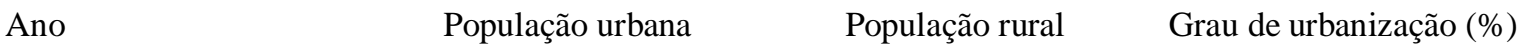

1918 1.000 3000 25 


\begin{tabular}{|lccc|}
\hline & $\begin{array}{c}\text { XVII Simpósio Brasileiro } \\
\text { de Geografia Fisica Aplicada }\end{array}$ & $\begin{array}{r}\text { OS DESAFIOS DA GEOGRAFIA FíSICA NA FRONTEIRA DO CONHECIMENTO } \\
\text { I Congresso Nacional } \\
\text { de Geografia Física }\end{array}$ & $\begin{array}{c}\text { Instituto de Geociências - Unicamp } \\
\text { Campinas - SP } \\
\text { 28 de Junho à 02 de Julho de 2017 }\end{array}$ \\
\hline 1940 & 6.666 & 6.547 & 50.7 \\
1950 & 13.457 & 7.628 & 62.2 \\
1960 & 25.762 & 8.940 & 74,8 \\
1970 & 41.059 & 8.134 & 83,4 \\
1980 & 52.698 & 7.060 & 88.21 \\
1991 & 70.399 & 6.235 & 91.86 \\
2000 & 90.696 & 3.172 & 94.58 \\
2010 & 103.035 & 3.091 & 97,4 \\
\hline
\end{tabular}

Fonte: BOSCARIOL, 2008. Organização: MORAES, 2016.

Com o crescimento populacional urbano foram necessários investimentos em infraestruturas de transporte intra-urbano, asfaltamento viário, ampliação da oferta de água tratada e rede de esgoto, Boscariol (2008).

Com a chegada a década de 1950, Ourinhos passa por significativa reestruturação urbana. A diferenciação socioeconômica cria a demanda crescente por moradias tanto de padrão popular quanto de alto padrão, as famílias mais abastadas migraram para a porção oeste do município, onde foram construídas residências de alto valor; a região lindeira à Santa Casa se tornou espaço de atração de serviços ligados à saúde, notadamente no que diz respeito a clínicas médicas de várias especialidades que atendem pessoas de várias cidades da região; a região central, nas proximidades do pátio de manobras da linha de ferro, principalmente ao norte desta, se tornou um espaço relativamente depreciado, recebendo atividades econômicas como brechós, bares e lojas de móveis usados, por exemplo, além de abrigar também residências, Boscariol (2008).

Houve uma tentativa de incentivar a verticalização do município na década de 1980, tanto para fins comerciais quanto residenciais, porém, os investimentos feitos não foram tão felizes quanto o esperado, uma vez que havia espaço para a expansão horizontal e o preço da terra mostrava-se acessível. Além disso, com a construção de casas evita-se o pagamento de condomínio, por exemplo. Sendo assim, apesar de ter atualmente, de acordo com o IBGE, possuir 111.056 mil habitantes, o número de edifícios no município não completa uma dezena, Boscariol (2008). 
Com a chegada das últimas décadas do século XX e o início do século XXI a economia ourinhense sofreu grande impacto e isso afetou a produção do espaço urbano. Grandes empresas como a Bunge, produtora de soja, abandonaram o município, diminuindo a arrecadação fiscal. Aliado a isso houve diminuição do fluxo comercial entre Ourinhos e o Norte do Paraná pelo estabelecimento de uma praça de pedágio entre os Estados de São Paulo e do Paraná, Boscariol (2008).

É neste momento também que surge em Ourinhos uma nova tendência, a construção de condomínios fechados. O primeiro deles foi o "Royal Park", na zona Oeste da cidade, atualmente estão em fase de implantação os condomínios "Ville de France", na porção Sudeste e o "Recanto dos Pássaros", na porção Norte da zona urbana.

\section{Recortes temporais de ocupação da microbacia do córrego Águas da Veada}

\section{A) 1954 a 1963}

Neste momento o crescimento urbano ourinhense se manteve forte, assim como na década anterior, porém, a tendência de expansão se volta ao setor Oeste, surgindo novos bairros como os Jardins Paulista (1957), Ouro Verde (1959) e das vilas Nossa Senhora de Fátima (1961) e São Francisco. Apenas uma pequena parte da microbacia do Águas da Veada foi ocupada nessa época, Boscariol (2008).

\section{B) 1974 a 1983}

Nos anos finais da década de 70 foram criados vários bairros, dentre eles Vila Brasil II, III e IV (1976) e Jardim Primavera (1975), por exemplo. No ano de 1980 foi criado o Distrito Industrial I. No mesmo ano surge o Jardim Guaporé na porção Norte da área urbana. Este é um dos bairros mais pobres de Ourinhos, com graves déficits de energia, água e esgoto sanitário. Neste período foi marcante a expansão no sentido Leste-Oeste, houve também crescimento no sentido Norte-Sul, ainda que menos significativo. Todo o setor Sul, assim como também da microbacia em estudo, foram ocupados neste período, no entanto, faz-se uma diferenciação importante nos tipos e densidades de ocupação das duas regiões. Enquanto o Sul é marcado pela densa ocupação urbana para fins habitacionais, o norte apresenta ocupação bem menos densa e as atividades principais desenvolvidas no referido setor estão ligadas à indústria e à prestação de serviços. Destacamos também que o trecho central da microbacia ocupado durante este período é classificado como urbano, no entanto apresenta grandes vazios e é ocupado em grande parte por chácaras, Boscariol (2008). 


\section{C) 1994 a 2005}

Segundo a Lei 6.766 de dezembro de 1979, a subdivisão da gleba urbana em lotes exige a implantação de infraestrutura, logo, passou a haver maior rigor legal em relação à criação de novos loteamentos, tornando imprescindíveis equipamentos urbanos como asfaltamento, rede de esgoto, água e energia elétrica. Todas essas responsabilidades passaram a ser das empresas loteadoras, encarecendo o processo e levando as mesmas a realizarem estudos de viabilidade voltados a públicos específicos. Além de diminuir o tamanho dos lotes, para baratear seu preço, houve um decréscimo no volume de novos loteamentos. Apesar disso surgiram novos bairros populares nos setores Sudeste e principalmente no Sudoeste da microbacia, como é o caso dos bairros Residencial Parque dos Diamantes, Jardim São Judas Tadeu, Santa Fé e Santa Fé IV. Juntamente ao período de 74 a 83 este foi o momento de maior pressão urbana sobre a microbacia do Águas da Veada, Boscariol (2008).

\section{D) 2006 a 2016}

As observações em campo e as análises de imagens de satélite levaram à constatação de que na última década o município passou por um significativo aumento da mancha urbana, especialmente no que se refere a residenciais fechados. Na porção norte foi estabelecido o bairro Parque Trianon; no setor sudeste foi criado o bairro Ville de France, tendo este uma parte fechada e outra parte aberta, neste bairro fica também o novo campus da UNESP, ainda em construção; a porção Sul da malha urbana abriga o residencial fechado Moradas Ourinhos II; já no setor Nordeste a expansão sobre a microbacia do Águas da Veada foi pouco significativa com apenas um pequeno trecho.

\section{Métodos e técnicas da elaboração cartográfica}

A base para a produção da representação cartográfica foi um arquivo no formato dwg fornecido pela Secretaria do Planejamento da Prefeitura Municipal de Ourinhos. Os dados foram convertidos para o formato shp no programa ArcGis 10, ao qual nomeamos "evolução". Para classificar os bairros de acordo com a cronologia de sua criação foi inserido um campo chamado "data" na tabela de atributos do shape (figura 2). Neste campo deu-se entrada às seguintes datas: 1944; 1953; 1963; 1973; 1983; 2006; e 2016. Datas que representam os limites superiores do intervalo de classes estabelecido. 


Table
evolução
\begin{tabular}{|c|c|c|c|c|}
\hline \\
\hline Fil & Shape & Id & data & \\
\hline 57 & Polygon & 0 & 1944 & misto \\
\hline 58 & Polygon & 0 & 1944 & comercial \\
\hline 59 & Polygon & 0 & 1944 & misto \\
\hline 60 & Polygon & 0 & 1944 & comercial \\
\hline 61 & Polygon & 0 & 1944 & comercial \\
\hline 62 & Polygon & 0 & 1944 & comercial \\
\hline 63 & Polygon & 0 & 1944 & comercial \\
\hline 64 & Polygon & 0 & 1944 & comercial \\
\hline 65 & Polygon & 0 & 1944 & misto \\
\hline 66 & Polygon & 0 & 1944 & misto \\
\hline 67 & Polygon & 0 & 1944 & comercial \\
\hline 68 & Polygon & 0 & 1944 & comercial \\
\hline 69 & Polvoon & 0 & 1944 & comercial \\
\hline
\end{tabular}

Figura 2: inserção das datas na tabela de atributos. Fonte: MORAES, 2016.

Acessando as propriedades do shape e escolhendo a aba "symbology", selecionamos como parâmetro o campo "data" e pedimos para que o programa represente a informação através da escala monocromática (figura 3), de acordo com os intervalos determinados.

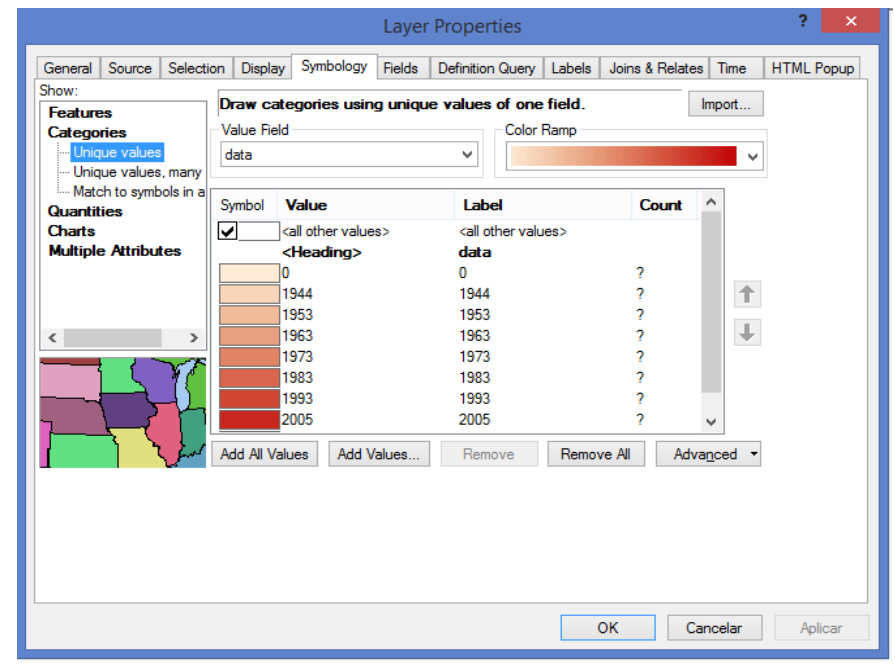

Figura 3: Representação dos intervalos de classes através da escala monocromática. Fonte: MORAES, 2016

A sequência do trabalho consistiu no recorte do shape com base na microbacia do córrego Águas da Veada. O resultado foi que apenas os intervalos entre 1954/63; 74/83; 94/2005; e 2006/16 interferiram na área de estudo (figura 4). 

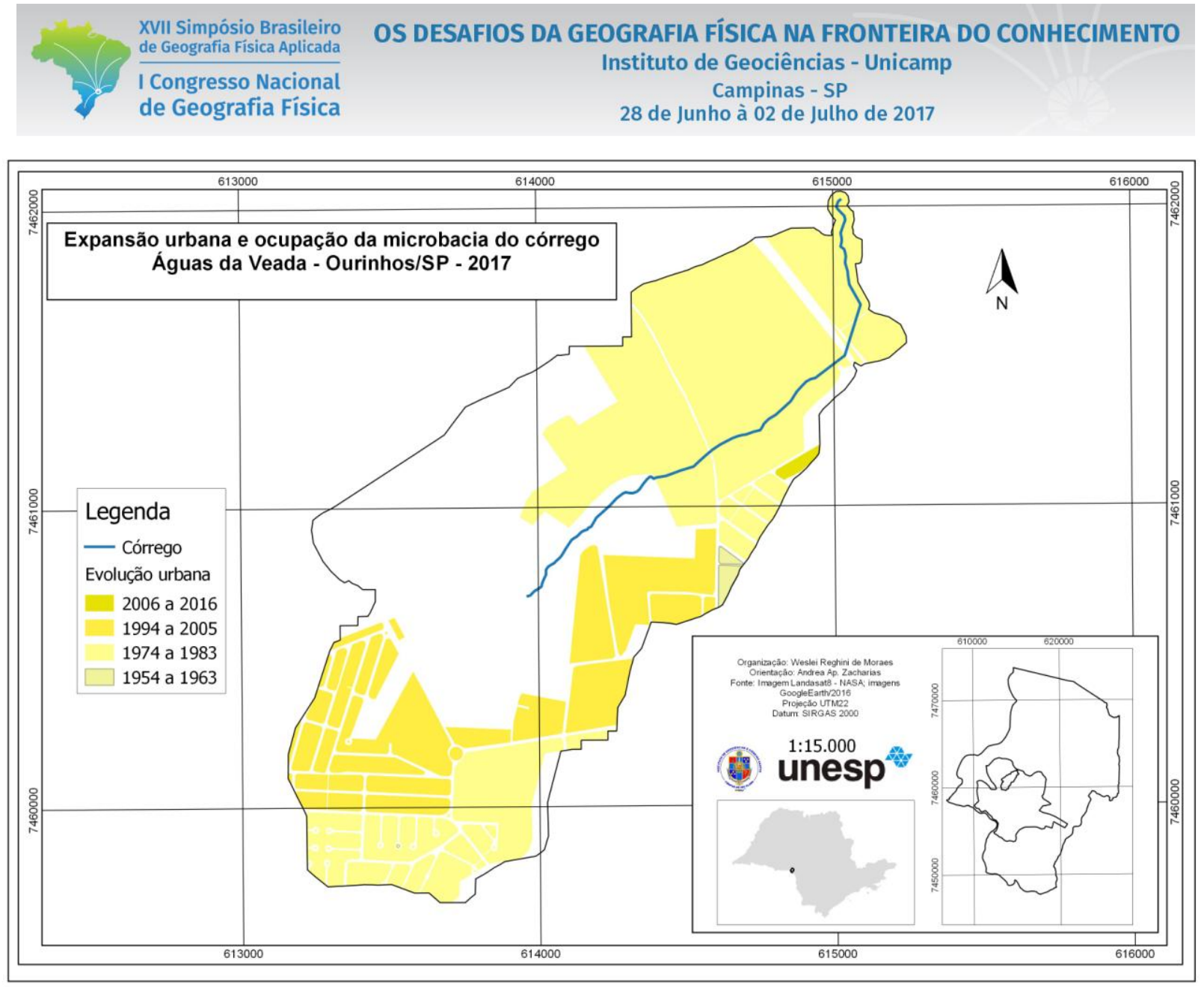

Figura 4: Expansão da mancha urbana na microbacia do córrego Águas da Veada. Fonte: MORAES, 2017.

O crescimento urbano trouxe sérios prejuízos à área de estudo causando impactos ambientais como desmatamento, acúmulo de lixo, voçorocamento e assoreamento do córrego Águas da Veada. Em 2013 uma das tentativas de contenção da voçoroca foi depositar rejeitos de materiais de construção na área erodida, sendo que tal medida mostrou-se completamente equivocada e inútil, uma vez que o quadro erosivo não apresentou melhoras, além de agregar o problema do lixo a uma área já fragilizada ambientalmente. Além disso soma-se à erosão o problema do lixo, que criou um grande depósito tecnogênico. Destacamos também que apesar de estar na zona urbana, a microbacia passou pelo estabelecimento da silvicultura de eucalipto. 


\section{Resultados}

Estudando o histórico de formação do espaço geográfico de Ourinhos foi possível compreender que motivos levaram à sua atual configuração, quais os agentes e interesses envolvidos neste processo e as razões pelas quais os impactos ambientais se manifestam em quantidade e intensidade. Como resultado deste estudo temos o mapa da microbacia do córrego Águas da Veada que demonstra os momentos de maior e menor expansão em direção a este setor da zona urbana ocorreram.

Na década de 50 a ocupação urbana foi muito pequena, enquanto no decênio de 70 foi mais intensa, abrigando residências populares. A década de 90 parece também expressar grande crescimento urbano, porém, não podemos deixar de destacar que os locais representados neste recorte temporal são marcados por significativos vazios urbanos, caracterizados em grande parte por chácaras e pastagens. Isso pôde ser comprovado através de vivências e visitas ao campo.

Na primeira década do século XXI a microbacia recebe vários loteamentos de caráter popular, estando presentes também várias áreas de recreação e lazer como quadras e campos de futebol.

Observamos que a utilização da escala monocromática se fez satisfatória na representação da expansão urbana na área de estudo.

\section{Considerações finais}

A microbacia do córrego Águas da Veada sofreu várias transformações ao longo da história de formação do espaço urbano ourinhense, recebendo intervenções que trouxeram diversos impactos ambientais. $\mathrm{O}$ estudo dessas transformações e sua representação na forma de mapa auxilia na compreensão do espaço geográfico da microbacia e no planejamento de ações que possam contribuir com sua recuperação ambiental. Neste estudo o Sistema de Informação Geográfica foi fundamental porque permitiu integrar e representar as informações socioespaciais relevantes à proposta de trabalho. 
XVII Simpósio Brasileiro de Geografia Fisica Aplicada

I Congresso Nacional de Geografia Física
OS DESAFIOS DA GEOGRAFIA FÍSICA NA FRONTEIRA DO CONHECIMENTO

Instituto de Geociências - Unicamp

Campinas - SP

28 de Junho à 02 de Julho de 2017

\section{Bibliografia}

BOSCARIOL, R. A. 2008. 250f. Formação socioespacial e expansão urbana do município de Ourinhos/SP. Trabalho de Conclusão de Curso (Graduação em Geografia) - Campus Experimental de Ourinhos - UNESP/SP. 2009.

CONTE, H. C.; FRESCA, T. M. Cidades médias: percursos conceituais e dealidade - o exemplo de Foz do Iguaçu - PR. Revista Geografar. Curitiba, v. 6, n.1, p. 192-211, jun./2011.

DEL RIOS, J. Ourinhos: Memórias de uma cidade paulista. Ourinhos, SP: Prefeitura Municipal, 1992. P. 255.

FILHO, O. M.; SERRA, R. V. Evolução e perspectivas do papel das cidades médias no planejamento urbano e regional. In: ANDRADE, T. A.; SERRA, R. V. Cidades médias brasileiras. Rio de Janeiro, IPEA, 2001. Capítulo 1, p. 1 a 34.

MARTINELLI, M. Cartografia dinâmica: tempo e espaço nos mapas. Geousp - Espaço e tempo, São Paulo, № 18 , pp. $53-66,2005$.

SOARES, B. R. Repensando as cidades médias brasileiras no contexto da globalização. Uberlândia - MG:

Universidade Federal de Uberlândia, 18 de jun. de 1998. Palestra ministrada junto ao Programa de Pós Graduação em Geografia. 